\title{
Subdesenvolvimento e dependência na economia política do Brasil
}

\author{
Underdevelopment and dependency in Brazil's political economy
}

Luiz Maurício Bentim da Rocha Menezes

Instituto Federal de Educação, Ciência e Tecnologia do Triângulo Mineiro (IFTM) lmbrmenezes@yahoo.com.br

\author{
Maria Elizabeth Bueno de Godoy \\ Universidade de São Paulo \\ mariebueno70@gmail.com
}

Resumo: Nosso trabalho pretende investigar o problema do subdesenvolvimento brasileiro a partir do diálogo entre as obras "O mito do desenvolvimento econômico" (1974) de Celso Furtado e "Dialética da Dependência" (1973) de Ruy Mauro Marini. O intuito é apresentar a complexidade das obras em suas análises sobre capitalismo global e demonstrar a crise que se encontra o Brasil hodierno, a partir de um balanço da economia política desenvolvida no país na segunda metade do século XX, referência para as obras tratadas neste artigo. O resultado é a marca do subdesenvolvimento e da dependência devido a mesma escolha que perpetua na dinâmica do país: ser mero exportador de commodities agrícolas e minerais, falta de investimento na indústria nacional e a produção de mais-valia para os países desenvolvidos a partir da exploração da mão-de-obra não especializada dos trabalhadores do país. Por fim, iremos relacionar com alguns países da América Latina para demonstrar que essa política adotada não é exclusiva do Brasil.

Palavras Chaves: Mito do Desenvolvimento, Teoria da Dependência, Economia Política.

\begin{abstract}
This paper aims at investigating the problem of the Brazilian underdevelopment established on the dialogue between Celso Furtado's work "The Myth of Economic Development" (1974) and Ruy Mauro Marini's "Dialectics of Dependency" (1973). Its objective is to present the complexity of both works on global capitalism and to present the ongoing crisis in Brazil, from the balance of an economy agenda developed since the late twentieth century. The result is the underdevelopment and dependence due to the same choices being made for the country's dynamics: to be the simple producer of mineral and grain commodities, the lack of investment in the national industry, and the production of surplus value for the centre countries, which is based on the non-skilled Brazilian working force. Finally, it establishes an analogous relation to some of the countries in Latin America to prove that this adopted politics is not exclusive to the Brazilian case.
\end{abstract}

Keywords: Myth of Development, Theory of Dependence, Political Economy. 


\section{Introdução}

O Brasil passa por um período de ajustes após a disputa eleitoral de 2018 para presidência da República. Com a criação do ministério da economia e a ascensão de Paulo Guedes como ministro, tivemos uma brusca mudança para uma política econômica ultra liberal que defende, entre outras coisas, o Estado mínimo, as privatizações, a desregulamentação do trabalho e o mercado financeiro como regulador das decisões econômicas. Somado a isso, temos o destaque para o novo coronavírus (covid-19) que ganhou força no final do ano 2019. O vírus ganhou seu nome científico de SARS-CoV-2 (Coronavírus da síndrome respiratória aguda grave 2) e tem um alto nível de contágio. A Organização Mundial da Saúde (OMS) definiu que a doença respiratória provocada pela infecção do novo coronavírus deverá ser chamada de Covid19. O contágio ganhou dimensões globais em 2020 e não demorou muito para que a OMS declarasse que vivíamos uma forte pandemia em todo o mundo. Aos poucos cidades, estados e países começaram a fechar suas fronteiras e a restringir a locomoção das pessoas, recomendando, ou até mesmo decretando, que as pessoas ficassem em casa para evitar a disseminação do vírus entre as pessoas, em uma tentativa de achatar a curva de contaminação. Tais medidas foram determinantes para limitar o livrecomércio, afetando seriamente a economia dos países e os dogmas liberais anteriormente defendidos. O mundo passa por uma forte desaceleração e os índices de crescimento global são negativos.

Para analisarmos a economia política brasileira atual, optamos por fazer a retomada dos estudos de Celso Furtado e Ruy Mauro Marini, importantes pensadores da problemática econômica, política e social do país. Dessa forma, pretendemos demonstrar que há uma continuidade nos processos decisórios que levaram à presente situação, investigando, a partir desses autores, possíveis soluções para o subdesenvolvimento do Brasil rumo a um projeto de nação.

Celso Furtado viveu em um período histórico, do fim da Segunda Guerra Mundial até a primeira crise do petróleo, que ficou conhecido como "a era de ouro do capitalismo". Tratou-se de um período marcado pelo processo de produção e consumo em massa e intervencionismo do Estado na economia. Foi uma era de intenso crescimento econômico no Brasil, durante o governo de Juscelino Kubitschek, 50 anos em 5 (1956-1961). Furtado criou a pedido do presidente Juscelino Kubitschek, em 1959, 
a Superintendência de Desenvolvimento do Nordeste (SUDENE) que tem por finalidade promover o desenvolvimento includente e sustentável do Nordeste. Em 1962, foi ministro do planejamento do governo João Goulart e idealizador do Plano Trienal de Desenvolvimento Econômico e Social. No período militar, Celso Furtado teve seus direitos políticos cassados por dez anos e se exilou no exterior. Após a reabertura democrática, Celso Furtado voltou a exercer as suas atividades profissionais. Faleceu em novembro de 2004.

Ruy Mauro Marini inicia sua carreira acadêmica a partir de 1962 como professor universitário na UnB. Exilou-se no México e no Chile após o golpe militar de 1964 no Brasil. Conhecido por desenvolver a teoria da dependência, que consiste em uma leitura crítica e marxista dos processos de reprodução do subdesenvolvimento na periferia do capitalismo mundial (OURIQUES, 1995), Marini escreveu diversos trabalhos que analisavam o papel dos países latino-americanos com relação a sua dependência ao capital dos EUA. A maioria de suas obras permanecerem inéditas em português até sua morte em 1997.

Apesar das diferenças entre esses pensadores, gostaríamos de destacar os pontos convergentes que há como, por exemplo, a reflexão que ambos fazem sobre o desenvolvimento como critério fundamental para o progresso técnico e o aumento da produtividade (SILVA; PARANÁ, 2017: 206). Nosso trabalho pretende investigar o problema do subdesenvolvimento brasileiro a partir do diálogo entre as obras "O mito do desenvolvimento econômico" (1974) de Celso Furtado e "Dialética da Dependência" (1973) de Ruy Mauro Marini. O intuito é apresentar a complexidade das obras em suas análises sobre capitalismo global nos anos 1970 devido à intensificação das formas de acumulação de capital, seja pelas empresas transnacionais ou pelo capital financeiro; e demonstrar a crise que se encontra o Brasil hodierno, a partir de um balanço da economia política desenvolvida no país na segunda metade do século $\mathrm{XX}$, referência para as obras tratadas neste artigo. O resultado é a marca do subdesenvolvimento e da dependência devido a mesma escolha que perpetua na dinâmica do país: ser mero exportador de commodities agrícolas e minerais, falta de investimento na indústria nacional e a produção de mais-valia ${ }^{1}$ para os países desenvolvidos a partir da exploração da mão-de-obra não especializada dos trabalhadores do país. Por fim, iremos relacionar

\footnotetext{
${ }^{1}$ Apesar das edições mais recentes das obras de Marx no Brasil feita pela editora Boitempo utilizarem a palavra "mais-valor" para traduzir o termo consagrado por Marx em seus livros, optamos por manter "mais-valia" da maneira como o termo é encontrado na obra de Marini utilizada neste trabalho.
} 
com alguns países da América Latina para demonstrar que essa política adotada não é exclusiva do Brasil.

\section{Subdesenvolvimento e Dependência}

O cenário atual de análise da conjuntura brasileira que partimos são últimas eleições presidenciais (2018) e a chegada de Bolsonaro ao poder. Somado a isso, temos o advento da pandemia de covid-19 que trouxe sérios danos à economia global como um todo a partir do início do ano 2020. Ajustes tiveram que ser feitos aos processos do capitalismo perante o fechamento das fronteiras entre países e a recomendação de que a maioria das pessoas ficasse em casa para a prevenção contra o vírus. No Brasil, as medidas tomadas pelo ministério da saúde junto aos governos federal, estaduais e municipais foram insuficientes para conter a disseminação da doença no país. No momento em que escrevemos este artigo, o Brasil ocupa o $2^{\circ}$ lugar em número de infecções por covid-19 no mundo, ultrapassando a marca de cinco milhões de casos $\operatorname{confirmados}^{2}$, atrás apenas dos EUA, e o $5^{\circ}$ país do mundo a registrar mais de mil mortes de covid-19 em um dia (SANDES, 2020), números esses assustadores. Não podemos simplesmente readaptar a rotina do trabalho e dizer que "tudo vai ficar bem". Especula-se que a economia da América Latina sofrerá uma contração de atividade de 5,3\% em 2020, gerando por volta de 30 milhões a mais de pessoas pobres (CEPAL, 2020: 15). Para acentuar ainda mais o caso, temos a saída massiva de investidores estrangeiros de mercados emergentes (AGUILA, 2020), o que ajudou a agravar ainda mais a situação. Diante desse cenário, é preciso reavaliar o papel dos países em desenvolvimento / subdesenvolvidos, incluído o Brasil. O que nos leva a retomar dois grandes pensadores do país: Celso Furtado e Ruy Mauro Marini, que tiveram a árdua tarefa de "compreender o capitalismo brasileiro - seu subdesenvolvimento, seu caráter dependente, a qualidade de sua burguesia - não apenas no que tem de capitalista, mas também, especificamente, no que tem de brasileiro, na sua particularidade histórica e geográfica" (FURNO, 2020).

\footnotetext{
2 Segundo o site oficial do governo: Coronavírus Brasil, consultado em 14/10/2020, o país tinha 5.140.863 casos confirmados de Covid-19 com 151.747 mortes.
} 
De acordo com Celso Furtado, os mitos são um reflexo da realidade objetiva (1974: 13). Isso significa dizer que o mito retrata como real aquilo que é meramente uma imagem dos fatos, uma construção discursiva da realidade e que não passa de um simulacro que engana aqueles que acreditam em sua veracidade. Quando se trata da economia política, o simulacro construído funciona como um véu que pretende ocultar em seu discurso as tramas sutis da produção capitalista. O Brasil é um país que tem um passado de alinhamento com os EUA que vem prejudicando historicamente o seu crescimento. Ocupando atualmente o lugar da $9^{\text {a }}$ economia do mundo, o Brasil poderá cair em breve para a $12^{\mathrm{a}}$ posição (COSTA, 2020). Apesar de haver uma influência da pandemia de covid-19 e a diminuição dos setores produtivo e comércio do país, a escolha do modelo econômico adotado é fundamental para o presente resultado. A economia norte-americana é dependente de recursos não renováveis produzidos no exterior (FURTADO, 1974: 15-16), o que faz com que haja uma procura por tais produtos nos países subdesenvolvidos. No caso brasileiro, há uma escolha recorrente por ser exportador de commodities agrárias e minerais que é insuficiente para alavancar o crescimento do país à categoria de país desenvolvido. O setor industrial ainda é o que mais pesa economicamente em uma comparação entre nações, sendo que o Brasil se encontra muito inferior no aprimoramento deste setor. A substituição de importações, que visa dar incentivos para a indústria nacional para que ela possa crescer, é característica própria das economias subdesenvolvidas (FURTADO, 1974: 24) e pouco eficaz para alavancar a economia desses países (GALA, 2020), o que leva, no Brasil, ao seu inevitável abandono como um projeto econômico viável para se desenvolver por meio de acordos internacionais e da ampliação de seu comércio com o resto do mundo. (ELIAS, 2020).

As formas de consumo definidas pelos países desenvolvidos são inviáveis dentro das possibilidades evolutivas do sistema capitalista. Os recursos não renováveis são um grande problema dentro desse sistema que explora cada vez mais a natureza como um recurso infinito. Como já é longamente conhecido, os recursos naturais têm uma durabilidade incompatível com o modelo exploratório desse modo de produção. Portanto, é mais importante repensar a própria estrutura desse modelo do que a formulação de discursos que visem incentivar aos países subdesenvolvidos a alcançar um mesmo padrão de exploração de recursos, pois seria completamente insustentável. 
O interesse principal do modelo que leva a essa ruptura cataclísmica está em que ele proporciona uma demonstração cabal de que o estilo de vida criado pelo capitalismo industrial sempre será o privilégio de uma minoria. O custo, em termos de depredação do mundo físico, desse estilo de vida é de tal forma elevado que toda tentativa de generalizá-lo levaria inexoravelmente ao colapso de toda uma civilização, pondo em risco as possibilidades de sobrevivência da espécie humana. Temos sim a prova definitiva de que o desenvolvimento econômico - a ideia de que os povos pobres podem algum dia desfrutar das formas de vida dos atuais povos ricos - é simplesmente irrealizável. (FURTADO, 1974: 74-75)

O mito do desenvolvimento se encontra na crença de que os países periféricos possam atingir o mesmo patamar dos países de centro apenas seguindo o mesmo modelo econômico perpetrado por eles. O processo de acumulação amplia o fosso entre o centro capitalista e as economias periféricas, cujas disparidades continuam a agravarse (FURTADO, 1974: 68). O fluxo contínuo e a busca incessante pelo crescimento contínuo ano após ano fazem do processo de acúmulo de capital uma verdadeira Hidra de Lerna, em que a cabeças do capital não param de se duplicar. Mas o problema não gira em torno do acúmulo apenas, mas da concentração e da falta de distribuição de renda, o que pode ser facilmente percebido no caso brasileiro.

Em um país como o Brasil basta concentrar a renda (aumentar o consumo supérfluo em termos relativos) para elevar a taxa de crescimento do PIB. Isto porque, dado o baixo nível médio de renda, somente uma minoria tem acesso aos bens duráveis de consumo e são as indústrias de bens duráveis as que mais se beneficiam de economias de escala. Assim, dada uma certa taxa de investimento, se a procura de automóveis cresce mais que a de tecidos (supondo-se que os gastos iniciais nos dois tipos de bens sejam idênticos), a taxa de crescimento será maior. Em síntese: quanto mais se concentra a renda, mais privilégios se criam, maior é o consumo supérfluo, maior será a taxa de crescimento do PIB. Desta forma a contabilidade nacional pode transformar-se num labirinto de espelhos, no qual um hábil ilusionista pode obter os efeitos mais deslumbrantes (FURTADO, 1974: 118).

Celso Furtado considera o subdesenvolvimento como uma forma de organização social no interior do modo de produção capitalista, como um processo estrutural 
específico e não uma etapa de transição como podem suscitar os termos "emergente" e “em desenvolvimento". O subdesenvolvimento é processo próprio de um país desigual, com alta concentração de renda e uma burguesia que se nega a renunciar aos seus privilégios para uma equalização das mazelas do país. No início da pandemia de covid19, enquanto petróleo e outras commodities despencavam no mercado financeiro, o ouro se manteve em alta. Atualmente, a moeda utilizada nos Estados é baseada no sistema de crédito e, portanto, tem sua confiança garantida nos títulos que emite, já que não é lastreada em nenhum metal. Mas em épocas de crise, se procura confiar novamente nos metais ao invés dos títulos emitidos pelo tesouro, pois, de acordo com Marx,

o crédito, sendo [...] uma forma social de riqueza, desloca o dinheiro e usurpa sua posição. É a confiança no caráter social da produção que faz com que a forma-dinheiro dos produtos apareça como algo meramente evanescente e ideal, como uma mera noção. Mas tão logo o crédito é abalado, e essa é uma fase regular e necessária no ciclo da indústria moderna, supõe-se que toda riqueza real é efetiva e repentinamente transformada em dinheiro, em ouro e prata - uma demanda insana, mas que surge necessariamente do próprio sistema. E o ouro e a prata necessários para satisfazer essa imensa demanda atingem o valor de alguns milhões no cofre do banco. (MARX, 2017: 708)

Mesmo não conhecendo a moeda fiduciária, Marx conseguiu prever o quanto o capitalismo precisaria se libertar da moeda-mercadoria para continuar a crescer indefinidamente, apesar de demonstrar o quanto esse crescimento exponencial seria um problema para o próprio capitalismo justamente pelo caráter usurpador do crédito. Ou seja, a moeda que não é baseada em nada além de títulos do tesouro, é uma moeda mais volúvel. Por um lado, isso possibilita um crescimento indefinido da economia, por outro lado, é um capital mais incerto e volátil, capaz de criar bolhas especulativas que podem vir a estourar a qualquer momento e causar uma crise da economia global, como o caso da crise de 2008, por exemplo. Segundo a linguagem marxiana, o crédito intensifica ainda mais a produção da mais-valia, isto é, o valor que é produzido em cima da força de trabalho não paga. Isso se intensifica nos tempos atuais com o aumento do volume de transações feitas no mercado financeiro. Nos Manuscritos, Marx dirá que 
Numa sociedade que se encontra em crescente prosperidade, apenas os mais ricos entre todos podem viver do juro sobre o dinheiro. Todos os outros obrigam-se, com o seu capital, a montar um negócio ou lançá-lo no comércio. Desta maneira, a concorrência entre os capitais torna-se, portanto, maior, a concentração dos capitais torna-se maior, os grandes capitalistas levam à ruína pequenos, e uma parte dos capitalistas de outrora baixa à classe dos trabalhadores, a qual, com esta entrada, sofre, em parte, novamente uma redução do salário e cai numa dependência ainda maior dos poucos grandes capitalistas. (MARX, 2004: 26-27)

A sociedade capitalista é uma sociedade inerentemente desigual. Em nome da liberdade econômica, os liberais se apoiam em uma farsa só posta às claras com uma crise. O capitalismo já passou por muitas crises e está passando por mais uma desde o avanço da pandemia e a paralisação dos mercados. É preciso avaliar que isso faz parte do próprio processo do capitalismo e não pode ser simplesmente ajustado. É um sistema que foi feito para beneficiar poucos em detrimento de muitos. Nesse ponto, os estudos de Furtado e Marini são essenciais para se entender o papel que cumpre a América 56 Latina como periferia da do centro capitalista norte-americano.

A participação da América Latina no mercado mundial contribuirá para o eixo da acumulação na economia industrial se desloque da produção de mais-valia absoluta a da mais-valia relativa, isto é, que a acumulação passe a depender mais do aumento da capacidade produtiva do trabalho do que simplesmente da exploração do trabalhador. (MARINI, 2000: 112-3)

Marini, utilizando os termos marxianos, irá explicar como se dá a exploração da América Latina no mercado mundial. Para isso, ele irá usar a noção de mais-valia absoluta e mais-valia relativa. Mas em que consistem esses conceitos? A mais-valia é o excedente do valor produzido em cima da exploração da força de trabalho, de maneira que esse valor excedente é trabalho não pago. Para isso, Marx irá dividir essas horas em dois tipos: (i) tempo de trabalho necessário, que corresponde ao valor da força de trabalho; e (ii) tempo de trabalho excedente, que é a mais-valia (MARX, 2013). A maisvalia absoluta é calculada em cima do número total de horas trabalhadas. Ex.1:

\begin{tabular}{|l|l|l|l|}
\hline Mais-valia & Tempo de trabalho & Tempo de trabalho & Total de horas \\
\hline
\end{tabular}




\begin{tabular}{|c|c|c|c|}
\hline Absoluta & necessário & excedente & trabalhadas \\
\hline Antes & $6 \mathrm{~h}$ & $2 \mathrm{~h}$ & $8 \mathrm{~h}$ diárias \\
\hline Depois & $6 \mathrm{~h}$ & $4 \mathrm{~h}$ & 10h diárias \\
\hline
\end{tabular}

Pela tabela acima, podemos verificar que o aumento de mais-valia foi decorrente do aumento do tempo de trabalho excedente, de maneira que há um aumento de horas totais, por isso chamada de mais-valia absoluta. Quanto à mais-valia relativa, essa corresponde ao aumento do tempo de trabalho excedente sem que o total de horas se altere. Ex.2:

\begin{tabular}{|c|c|c|c|}
\hline $\begin{array}{c}\text { Mais-valia } \\
\text { Relativa }\end{array}$ & $\begin{array}{c}\text { Tempo de trabalho } \\
\text { necessário }\end{array}$ & $\begin{array}{c}\text { Tempo de trabalho } \\
\text { excedente }\end{array}$ & $\begin{array}{c}\text { Total de horas } \\
\text { trabalhadas }\end{array}$ \\
\hline Antes & $6 \mathrm{~h}$ & $2 \mathrm{~h}$ & $8 \mathrm{~h}$ diárias \\
\hline Depois & $4 \mathrm{~h}$ & $4 \mathrm{~h}$ & $8 \mathrm{~h}$ diárias \\
\hline
\end{tabular}

Como podemos perceber, não houve alteração nas horas totais trabalhadas, mas, mesmo assim, houve um aumento no tempo de trabalho excedente, configurando em um aumento de mais-valia. Por ser um processo mais sutil, Marx optou por chamar de maisvalia relativa. Mas que poderia gerar essa modificação entre o valor real da força de trabalho e a mais-valia produzida em cima desse mesmo trabalho? Um dos fatores que podemos dar como exemplo é o aprimoramento dos meios de produção, como o uso de máquinas novas e mais velozes. A aceleração da produção permite que um volume maior de mercadorias seja produzido sem alteração no valor total. Então se antes o trabalhador produzia x mercadorias por um valor $\mathrm{y}$, agora ele produz $2 \mathrm{x}$ mercadorias pelo mesmo valor y. Há uma alteração no valor da força de trabalho, que diminui, mas não no tempo de trabalho, o que faz com que haja um aumento do trabalho excedente. “A mais-valia relativa está ligada indissoluvelmente, então, à desvalorização dos benssalário, para que concorre em geral, mas não forçosamente, a produtividade do trabalho". (MARINI, 2000: 115)

O ponto chave da percepção de Marini foi entender a configuração da produção de mais-valia relativa no mercado global através da exploração da força de trabalho dos países periféricos. Seu ponto de vista irá se centrar na relação entre EUA e América Latina, onde aquele explora a força de trabalho dos países desta. Uma configuração que 
torna a América Latina cada vez mais dependente dos recursos norte-americanos, além de gerar para os EUA uma mais-valia cada vez maior. "A industrialização latinoamericana corresponde assim a uma nova divisão internacional do trabalho, em cujo âmbito se transferem aos países dependentes etapas inferiores da produção industrial [...], reservando-se para os centros imperialistas as etapas mais avançadas [...] e o monopólio da tecnologia correspondente”. (MARINI, 2000: 145)

O que podemos perceber aqui é que a dinâmica traçada para os países periféricos é de pouca mudança e que há atavismos coloniais que se perpetuam há décadas, de maneira que o subdesenvolvimento do Brasil e outros países da América Latina é crônico e impossível de ser superado através da repetição da fórmula capitalista receitada pelos países de centro. $\mathrm{O}$ que também se deve à profunda dependência cultural e econômica dos países da América Latina em relação ao modelo de civilização industrial ocidental. Desse modo, podemos dizer que a ideia de Celso Furtado de que a periferia colonial subdesenvolvida transfere valor ao centro desenvolvido corrobora a teoria da dependência de Ruy Mauro Marini, o que nos leva a arriscar como conclusão parcial interrelação entre a obra de Furtado e a obra de Marini na análise da 58 dependência brasileira.

A perspectiva sistêmica que afinal integrou o Brasil aos quadros da divisão internacional do trabalho ocupou um espaço relevante nos estudos e teses de Celso Furtado, Fernando Henrique Cardoso, Florestan Fernandes e Fernando Novais. A zona de intersecção não se refere apenas as franjas da teoria da dependência, mas sim ao âmago dos conceitos e da sua formulação dialética. O diálogo de Ruy Mauro Marini com esse enfoque se acelera, por exemplo, nesta passagem: "Ninguém nega a influência dos fatores internacionais sobre as questões internas, principalmente quando se está em presença de uma economia das chamadas centrais, dominantes ou metropolitanas, e de um país periférico, subdesenvolvido. Mas, em que medida se exerce essa influência? Que força tem frente aos fatores internos específicos da sociedade sobre a qual atua?"3 A interação entre Marini e os historiadores, sobretudo do período colonial, refere-se à lógica da exploração do excedente (exclusivo) e, consequentemente, à fórmula encontrada pelas economias metropolitanas para impor um padrão de acumulação capitalista à periferia. (MUNTEAL, 2009)

\footnotetext{
${ }^{3}$ MARINI, 2000: 11.
} 
Munteal é um dos pesquisadores que aponta que a análise da teoria da dependência dentro da discussão historiográfica tem seus avanços intelectuais a partir dos estudos acerca do espaço colonial e as relações entre as metrópoles europeias e as colônias nas Américas. A empreitada investigativa teve forte influência sobre os trabalhos empreendidos em torno do subdesenvolvimento dos países periféricos da América Latina, o que pretendemos discorrer melhor em nosso próximo tópico.

\section{O cenário latino-americano: ressignificando dependências}

Em artigo recente publicado do sítio eletrônico do Instituto de Estudos LatinoAmericanos (IELA) da Universidade Federal de Santa Catarina, Rafael Cuevas Molina afirma: "As recorrentes crises capitalistas, cada vez mais frequentes em nossos dias, concentram riqueza e destroem trabalho" (MOLINA, 2020). Neste sentido, partindo da atual crise sanitária causada pela covid-19, Molina estabelece o diagnóstico complicador daquilo que se ressignifica na lógica da dependência, ampliado ao cenário econômico das nações latino-americanas. Como aponta Molina, "os que concentram a riqueza, aumentam-na; os que têm menos, perdem trabalho, vendo reduzida a jornada laboral e sofrendo com os encargos dos impostos" (MOLINA, 2020).

Sem intenção de esgotar o tema, nossa argumentação recorre às análises de Rafael Molina, Professor e pesquisador do Instituto de Estudos Latino-americanos da Universidade Nacional da Costa Rica, e Alejandro Acosta, sociólogo e editor do jornal Gazeta Revolucionária, para demostrar que a lógica que conforma a teoria da dependência encontra análogos vieses nas medidas adotadas/impostas a outros países da chamada Pátria Grande.

Publicadas em sítio eletrônicos de mídias independentes, institutos e universidades, as análises de ambos autores discorrem sobre o quadro de acirramento das políticas do grande capital internacional, que para evitar 'quebradeiras' nos moldes na crise de 2008, estabelece como "saída", afirma Acosta, "a política de guerra interna contra os trabalhadores e as massas, que tem como componente impor ditaduras militares sangrentas a la Pinochet, e fortalecer o fascismo nos países desenvolvidos" (ACOSTA, 2020), controlando, assim, o mercado internacional e repassando o ônus da crise para os trabalhadores. 
A pandemia do novo coronavírus reforçou, na verdade, a agudização da crise econômica e da desigualdade na América Latina e Caribe, nota Molina. Um quadro de desgaste piorado desde o início dos confinamentos, em que, segundo informe da Oxfam, já em meados de março, a riqueza dos multimilionários da região teria crescido $17 \%$. Em contrapartida, o prognóstico era de que 40 milhões de trabalhadores perderiam seus empregos e uma média de 52 milhões de pessoas se encontrariam na pobreza até o final do ano (MOLINA, 2020). Não obstante as tímidas medidas de alguns países como Argentina, Uruguai e Colômbia, o que observamos são os repasses do sacrifício e das austeras medidas de 'solidariedade' aos setores assalariados e de menor recurso. Neste ínterim, a análise de Molina e de Acosta se complementam:

A América Latina é alvo dos ataques do imperialismo norte-americano devido ao controle quase absoluto da região. Todos os países estão sendo colocados como suportes para as operações de resgate do grande capital, dos 30 mil monopólios que são controlados pelas 150 famílias que dominam o mundo. No Brasil, por meio da PEC (Proposta de Emenda Constitucional) 10-2020, a Constituição está sendo mudada para permitir que o Banco Central compre títulos públicos e das empresas, inclusive no exterior, o que implica em direcionar os US\$ 345 bilhões das chamadas reservas soberanas para as operações de resgate. Já foram repassados $R$ \$ 1,25 trilhão para o resgate dos grandes bancos; uma quantia muito próxima ao Orçamento Público Federal. A MP (Medida Provisória) 936 avança na "reforma" trabalhista e facilita o cancelamento dos contratos coletivos e a redução dos salários em até 75\%. (ACOSTA, 2020)

A descrição do quadro brasileiro acima exposta encontra ecos nas análogas medidas aplicadas pelas políticas de seus vizinhos. O cenário uruguaio, chileno e argentino, por exemplo, guardadas as especificidades de suas trajetórias e das medidas adotadas desde o início da crise sanitária, não foge àquilo que Acosta reforça no ilustrado acerca do Brasil.

No Uruguai, o governo de direita de Lacalle Pou - do conhecido Partido Blanco está aprovando a Lei Emergencial, que, segundo Acosta, contempla 457 artigos, "220 a mais que a Constituição" (ACOSTA, 2020), em clara ameaça à Carta vigente. Enquanto isso, setores da burguesia de esquerda e pequeno burguesa clamam à formação de uma Unidade Nacional. No caso argentino, mergulhado em uma crise que precede a 
pandemia de covid-19, o governo de Alberto Fernández adiou o pagamento da dívida do estado e intenciona esticar a dívida externa (soma de US\$ 400 bilhões), negociando o aumento dos juros junto ao FMI, em um roteiro de filme de horror para a economia argentina. A pergunta de Acosta, “Quem irá pagar a conta?”, reitera o abaixo referido por Molina.

As recorrentes crises capitalistas têm sempre essa consequência; aumentam a concentração do capital e empobrecem os amplos setores da população trabalhadora, seja porque lhes reduz o salário, ou pela destruição do emprego. A onda de pobreza que se abate sobre a América Latina nos regressará a índices críticos, anteriores à década de 1980. (MOLINA 2020)

Para Molina, a crise sanitária serve como catalisador à crise econômica instaurada, sem dúvida. Contudo, não pode ser tomada como a "causa mais verdadeira", numa alusão ao conceito de prophasis utilizado pelo historiador grego Tucídides ao separá-la das outras tantas causas da deflagração do conflito entre Atenas e Esparta, no século V a.C. (Tuc., I. 23, 6) ${ }^{4}$. E, reforça, na conclusão de seu argumento, identificando nas "perversidades do sistema neoliberal" o quadro de esgarçamento do tecido social diante do cenário atual, esta sim, a causa mais verdadeira: "Os grandes capitais sairão cada vez maiores e mais fortalecidos, e os governos os seguirão, recebendo "ajudas" às custas e, em detrimento, dos contribuintes" (MOLINA, 2020).

O caso chileno, amplamente analisado em alguns artigos recentes de Alejandro Acosta, foi objeto de sua mais recente reflexão, publicada no último dia 19 de junho sob o título "Chile: entre o coronavírus, a mentira, a fome e os protestos sociais". Nesta, o autor desfia uma trama que conecta as rebeliões de fins de 2019 contra o chamado piñerismo, a crise sanitária que as suprime, e as novas (recentes) manifestações nas ruas de Santiago. A pandemia promovendo uma espécie de peripécia trágica revelou todas as faces do sistema chileno, o acordão das elites a empurrar aos trabalhadores o ônus da crise econômica, e, neste sentido, o reforço das práticas em análogos ajustes, austeridades e medidas que aprofundam desigualdades e aumentam o caos social.

A Rebelião Popular que começou em outubro deixou claro o "modelo chileno" e expôs uma realidade que vínhamos denunciando há anos. O

\footnotetext{
${ }^{4}$ A citação no corpo textual segue o padrão para citação de obras clássicas gregas. (TUCÍDIDES, 2008)
} 
modelo teve que explodir com o grito de dignidade e, logo depois, de caminhar a realidade muito bem escondida com a publicidade de um modelo de sucesso. Veio à luz: Estamos com fome! Essa realidade tornou-se visível após o desenvolvimento da pandemia da covid-19. Naturalmente o sistema faz o que sempre faz, que é proteger a ditadura dos empresários e abandonar o povo à sua própria sorte. Meses antes, em meio a rebelião, políticos de todas as cores correram para assinar um acordo para ocultar as demandas populares e salvaguardar o sistema, prometendo reformar a Constituição. Mas, é claro, reformas e mudanças controladas pelo mesmo de sempre: a classe burguesa dos negócios aliou-se ao grande capital transnacional. (ACOSTA, 2020)

Para Acosta, as críticas de Michelle Bachellet ao governo de Piñera ilustram o caráter hipócrita e oportunista do corpo político chileno, encadeado na defesa dos interesses rentistas, dos empresários e na manutenção da lógica até aqui analisada neste artigo. O autor atribui à faceta chilena, nesse ínterim, o "pior rosto do neoliberalismo": mentiras na contabilização de infectados e mortos pelo vírus, protecionismo dos privilégios, arrocho imposto às classes trabalhadoras, fragilidade do sistema de saúde e penúria da população. O que marca o caso chileno é o recrudescimento de 'velhas' práticas renovadas. Violência, controle das manifestações e maior dependência do capital estrangeiro. (ACOSTA, 2020)

O cenário chileno revela uma das facetas mais cruéis do sistema neoliberal que a crise sanitária trouxe à tona, servindo-nos de arauto sinistro das análogas medidas impostas aos trabalhadores do Brasil desde o início da quarentena em desarticuladas políticas entre os governos estaduais, municipais e o governo federal. Mesmo que os números distem, seja em níveis de contaminação, quantidade de mortos e porcentagem de desempregados, as pesquisas revelam um saldo comum entre todos nós: o nível alarmante da desigualdade e da precariedade nas sociedades dos países periféricos. Portanto, conclui Acosta:

No Chile 30\% dos idosos são forçados a trabalhar. Existem 11,5 milhões de endividados e mais de 5 milhões de inadimplentes (estudantes, devedores de moradia, famílias que precisam de comida etc.), e 850.000 pessoas subempregadas. Devemos destacar que 54,3\% dos mais pobres do Chile são mulheres. Os números de desempregados já estão aumentando, contabilizado 
em dois milhões de pessoas durante a pandemia. Durante a crise o governo garantiu às empresas que elas não mexeriam no bolso, deixando milhares de imigrantes e migrantes chilenos na rua. Embora os dados não estejam atualizados, já havia entre 500.000 e 700.000 famílias desabrigadas, perfazendo um total de quase 4 milhões de pessoas. (ACOSTA, 2020)

Uruguai, Argentina e, sobretudo, o Chile revelam, para além de análogas asserções, a marca de um projeto contemplado na discussão teórica aqui encaminhada, corroborada nos quadros (mesmo em breves exposições) e análises de Molina e Acosta, e ressignificada no modelo que reforça dependências, acirra o controle sobre as massas e transfere aos setores mais vulneráveis da população dessas nações o ônus das recorrentes crises do sistema. Pela obra de Furtado, podemos ver que a aliança das elites com os interesses do capital internacional nos países latino-americanos tem estrita relação com o efeito mimetismo dos padrões de consumo de bens suntuosos, entendendo que esse processo foi replicado atualmente e permanece em descompasso com a idealização de um projeto nacional de desenvolvimento. Já Marini, ressalta a perspectiva das relações desiguais no capitalismo entre países desenvolvidos e os subdesenvolvidos, tendo como ponto fundamental as relações comerciais entre esses grupos de países. Há nessa perversa lógica o caráter de continuidade de velhas dinâmicas, a ilusão sempre ressignificada de um projeto emancipador para a América Latina, e a manutenção de antigos (sempre fortalecidos) privilégios. Até quando?

\section{Conclusão}

Nesse artigo tomamos o desafio de analisar o problema do subdesenvolvimento dos países da América Latina a partir do mito do desenvolvimento e da teoria da dependência através das obras de Celso Furtado e Ruy Mauro Marini. Sem exaurir a questão, nosso intuito foi trazer à tona problemática e comparar com o momento atual em que se encontra o cenário social, político e econômico das Américas. Primeiramente, olhando diretamente para o Brasil e sua dinâmica atual de submissão aos mandos e desmandos norte-americanos e, posteriormente, observando os demais países da América Latina centrando-se em alguns deles como exemplos concretos. 
Ao nos debruçarmos sobre o cenário latino-americano, recorremos às análises do historiador Rafael Cuevas Molina e do sociólogo Alejandro Acosta. Seus escritos acerca do quadro de agudização da crise social e econômica a partir do início da pandemia da covid-19, reforçam a lógica da dependência dessas nações na dinâmica das crises do sistema neoliberal, sobretudo após 2008. Observamos que no caso brasileiro, conforme o descrito por Acosta, as Medidas Provisórias e demais intervenções ao texto constitucional contemplavam o ajuste dos interesses que salvaguardassem a economia, no sentido da proteção dos privilégios rentistas e do repasse das contas da crise aos setores assalariados. A fragilização das leis trabalhistas e a flexibilização da proteção à classe trabalhadora reforça a lógica perversa do sistema.

Na breve exposição sobre o cenário político e da crise sanitária no Uruguai, concluímos que as alianças entre os setores da elite, aliados aos interesses do capital internacional agudizavam o esgarçamento social e a fragilidade dos trabalhadores. Tanto no governo de Lacalle Pou (Uruguai) quanto no de Fernández (Argentina) o adiamento do acerto das dívidas e a procrastinação do seu pagamento com novos acordos e juros contraídos, significava a maior deterioração do quadro político interno, com o repasse das contas aos populares.

Em suas crises o sistema neoliberal encontra saídas que reforcem a dependência dos países periféricos do capital estrangeiro, neste sentido, reiterando o controle sobre as políticas públicas desses países em que estejam contemplados os interesses, sobretudo, do imperialismo norte-americano. Portanto, no processo de agravamento da crise catalisado pelo surto pandêmico do novo coronavírus, vemos a ressignificação de dinâmicas velhas, com nova roupagem.

O caso chileno apresentado na leitura de Acosta ilustra bem a falácia neoliberal aplicada à periferia. O Chile figura, nesse ínterim, espécie de modelo que poderá se repetir ou aplicar ao Brasil e outros países da chamada Pátria Grande. Um corpo político corrupto, desonesto, mal intencionado, descompromissado com a integridade dos fatos e mesmo com a transparência no enfrentamento da pandemia, voltado às medidas de proteção dos privilégios, à concentração da riqueza e ao seu gradual aumento (conforme dados estatísticos sugeridos por Molina), são alguns dos sérios desafios postos à classe trabalhadora, à população mais pobre e àquela parcela já totalmente desprovida e fragilizada da população.

Vimos que, a exemplo da apropriação tucidideana da separação entre causas e causa mais verdadeira, a crise sanitária enfrentada pelos países latino-americanos não 
figura como esta última, mas sim a própria lógica perversa do neoliberalismo, cujas recorrentes crises reforçam sua dependência dos países centrais e estabelecem a estagnação, quando não a derrocada das classes assalariadas e dos setores mais pobres da população desses países.

Pelas obras de Celso Furtado e Ruy Mauro Marini pudemos comparar o triste retrato do Brasil junto aos demais países da América Latina devido à continuidade de ser mero exportador de commodities agrícolas e minerais e a falta de investimento na indústria nacional, cedendo a força de trabalho dos seus trabalhadores para a geração de mais-valia para os países desenvolvidos perante a crescente exploração do sistema capitalista, o que fundamenta a continuidade desse modo de produção através do processo mercadológico e exploratório. Esses fatores somados constituem a marca do subdesenvolvimento e da dependência de todos os países periféricos nessa condição ${ }^{5}$.

\section{Fontes}

FURTADO, C. (1974 [1974]) O mito do desenvolvimento econômico. São Paulo: Círculo do Livro.

MARINI, R. M. (2000 [1973]). Dialética da Dependência. Rio de Janeiro; Buenos Aires: Vozes; CLACSO.

\section{Referências bibliográficas}

ACOSTA, A. (2020). Rebelião no Chile hoje. Brasil e América Latina amanhã. Papel da esquerda. Duplo Expresso, 13 mar. Disponível em: https://duploexpresso.com/?p=111139. Acesso em 15/08/2020.

ACOSTA, A. (2020). Quem está lucrando com o coronavírus? Duplo Expresso, 12 abr. Disponível em: https://duploexpresso.com/?p=112061. Acesso em 15/08/2020.

ACOSTA, A. (2020). Chile: Entre o coronavírus, a mentira e os protestos sociais. Duplo Expresso, 19 jun. Disponível em: https://duploexpresso.com/?p=113277. Acesso em $15 / 08 / 2020$.

AGUILA, N. (2020). Como o sistema financeiro está impedindo que a América do Sul enfrente a COVID-19. Jacobin Brasil, 23 jul. Disponível em: https://jacobin.com.br/2020/07/como-o-sistema-financeiro-esta-impedindo-que-aamerica-do-sul-enfrente-a-covid-19/. Acesso em: 09/08/2020.

BRESSER-PEREIRA, L. C. (2010). As três interpretações da dependência. Perspectivas, v. 38, p. 17-48.

CEPAL (2020). Dimensionar los efectos del COVID-19 para pensar en la reactivación. Informe Especial covid-19, n. 2, p. 1-21.

\footnotetext{
${ }^{5}$ Gostaria de agradecer ao auxiliar de pesquisa Antonio Godoy, assim como aos pareceristas anônimos que muito contribuíram para a melhora do artigo.
} 
COSTA, M. (2020). Brasil deve perder posto no top 10 das maiores economias. Veja, 14 mai. Disponível em: https://veja.abril.com.br/economia/brasil-deve-perderposto-no-top-10-das-maiores-economias/. Acesso em: 12/08/2020.

ELIAS, J. (2020). Estamos abandonando o modelo de substituição das importações, diz Troyjo. Exame, 19 fev. Disponível em: https://exame.com/economia/estamosabandonando-o-modelo-de-substituicao-das-importacoes-diz-troyjo/. Acesso em: $12 / 08 / 2020$.

FURNO, J. (2020) Contra o subdesenvolvimento brasileiro. Jacobin Brasil, 26 jul. Disponível em: https://jacobin.com.br/2020/07/contra-o-subdesenvolvimentobrasileiro/. Acesso em: 09/08/2020.

GALA, P. (2020). A substituição de importações não funcionou na América Latina. A promoção de exportações funcionou no Leste da Ásia. Paulo Gala / Economia \& Finanças, 30 jun. Disponível em: https://www.paulogala.com.br/o-modelo-desubstituicao-de-importacoes-nao-funcionou-no-brasil-e-na-america-latina-omodelo-de-promocao-de-exportacoes-funcionou-no-leste-da-asia-na-inglaterrana-alemanha-nos-eua-e-nos-paises-no/. Acesso em: 12/08/2020.

MARX, K. (2004). Manuscritos Econômico-Filosóficos. São Paulo: Boitempo.

MARX, K. (2013). O Capital, Crítica da Economia Política, v. I. São Paulo, Boitempo.

MARX, K. (2015). O Capital, Crítica da Economia Política, v. II. São Paulo, Boitempo.

MARX, K. (2017). O Capital, Crítica da Economia Política, v. III. São Paulo, Boitempo.

MOLINA, R. C. (2020). América Latina: concentrando riqueza. IELA, 03 ago. Disponível em: http://www.iela.ufsc.br/noticia/america-latina-concentrandoriqueza. Acesso em 15/08/2020.

MUNTEAL, O. (2009). Ser ou não ser subdesenvolvido: a dialética da dependência e a história do Brasil. In: SADER, E.; SANTOS, T. (Coord.). América Latina e os desafios da globalização. Ensaios em homenagem a Ruy Mauro Marini. Rio de Janeiro; São Paulo: Editora PUC-Rio; Boitempo, p. 317-331.

OURIQUES, N. D. (1995). La teoría marxista de la dependencia: una historia crítica. Tese (Doutorado em Economia). Universidade Nacional Autónoma de México.

PAINEL Coronavírus. (2020). Coronavírus Brasil, 14 out. Disponível em: https://covid.saude.gov.br/. Acesso em: 14/10/2020.

PLEIN, C.; FILIPPI, E. E. (2012). Do mito do desenvolvimento econômico ao mito do progresso: uma homenagem a Celso Furtado e Gilberto Dupas. Perspectiva Econômica, v. 8, n. 1, p. 13-23.

SADER, E.; SANTOS, T. (Coord.) (2009). América Latina e os desafios da globalização. Ensaios em homenagem a Ruy Mauro Marini. Rio de Janeiro; São Paulo: Editora PUC-Rio; Boitempo.

SANDES, A. (2020). Brasil é $5^{\circ}$ país do mundo a registrar mais de mil mortes de covid em um dia. UOL, 19 mai. Disponível em: https://noticias.uol.com.br/saude/ultimas-noticias/redacao/2020/05/19/brasil-e-o-

5-pais-do-mundo-a-registrar-mil-mortes-de-covid-19-em-umdia.htm?cmpid=copiaecola. Acesso em: 10/08/2020.

SANTOS, T. (2015). A Teoria da Dependência. Balanço e Perspectivas. Florianópolis: Editora Insular.

SILVA, L. T.; PARANÁ, E. (2017). Da dialética do desenvolvimento à dialética da dependência: o contínuo no descontínuo. Política \& Trabalho, n. 47, p. 191-208.

TUCÍDIDES. (2008). História da Guerra do Peloponeso. Livro I. Tradução e apresentação de Anna Lia Amaral de Almeida Prado. Texto grego estabelecido por Jaqueline de Romilly. São Paulo: Martins Fontes. 
Artigo recebido em 21 de agosto de 2020.

Aprovado em 23 de outubro de 2020.

DOI: 10.12957/intellectus.2020.53939 